\title{
Factors determining effectiveness of interferons in managing hepatitis C: new targets and new approaches
}

This article was published in the following Dove Press journal:

International Journal of Interferon, Cytokine and Mediator Research

29 July 2010

Number of times this article has been viewed

\author{
N Rajoriya' \\ Eleanor Barnes ${ }^{1,2}$ \\ 'Department of Pathogen Research, \\ Peter Medawar Building, South \\ Parks Road, Oxford, UK; ${ }^{2}$ Oxford \\ National Institute of Health Research \\ Biomedical Research Centre, \\ Oxford, UK
}

\begin{abstract}
The hepatitis $\mathrm{C}$ virus now infects 170 million people worldwide. The majority of infected people develop viral persistence that may lead to increasing liver fibrosis, liver cirrhosis, and hepatocellular cancer. Interferon therapy has been the mainstay of treatment for hepatitis $\mathrm{C}$ since the discovery of the virus in 1989. The introduction of a pegylated form of interferon that increases the half-life of interferon, and the concurrent use of ribavirin has significantly improved the likelihood of achieving long-term viral eradication. HCV genotype and viral load remain major determinants of response to interferons. However, very recently, host genetic polymorphisms linked to interferon- $\lambda 3$ have also been shown to play a crucial role in clinical outcome. A significant body of evidence now exists showing that the hepatitis $C$ virus has developed multiple strategies to subvert both the production and the antiviral effects of interferons. This review explores these strategies, the factors that determine the effectiveness of interferon therapy, and highlights novel interferons in development. Ultimately, given the significant side effect profile of interferon therapy, and the emergence of small molecules and therapeutic vaccines that may inhibit viral replication, the aim will be to achieve viral eradication without interferon treatment.
\end{abstract}

Keywords: hepatitis $\mathrm{C}$ virus, interferon, ribavirin, novel interferons, interferon- $\lambda$, pharmacodynamics

\section{Introduction}

Hepatitis $\mathrm{C}$ virus (HCV) infection is a worldwide epidemic that can be classified into six main genotypes based on sequence homology. The latest World Health Organization figures estimate that more than 170 million people ( $3 \%$ of the world's population) are infected with $\mathrm{HCV}^{1}{ }^{1}$ Of those acutely infected, $20 \%-50 \%$ of patients do not clear the virus and go on to develop persistent infection. Persistence of the virus in the long term is associated with the development of liver fibrosis, and eventually cirrhosis, with its inherent risk of life-threatening complications, including variceal bleeding and hepatocellular carcinoma. ${ }^{2}$

Since the discovery of HCV in 1989, interferons (IFNs) have been the cornerstone of therapy. IFNs are a family of cytokines first discovered by Isaacs and Lindenmann in 1957. ${ }^{3}$ They showed that virus-infected cells secrete a protein that inhibited viral replication in infected and uninfected cells. These proteins were called IFNs because they "interfered" with infection. IFNs have subsequently been found to have a broad spectrum of biologic activity. IFNs may be classified into Type I, Type II, and Type III, based on the receptor through which they signal. Type I IFNs bind to a specific receptor complex known as the IFN-AR receptor, and include IFN- $\alpha$, IFN- $\beta$, and IFN- $\omega$. In humans, Type II IFNs include IFN- $\gamma$ that binds to the receptor IFN-GR. Type I IFNs
Correspondence: E Barnes Department of Pathogen Research, Peter Medawar Building, South Parks Road, Oxford, OXI3SY, UK Tel +44 I865 27|I99 Email ellie.barnes@ndm.ox.ac.uk 
are known primarily for their ability to render cells resistant to viral infections and are produced by almost every cell in the body, whilst Type II IFN- $\gamma$ is produced only by T lymphocytes and natural killer (NK) cells. Type III IFNs include IFN- $\lambda$. This particular class of IFN is emerging as an exciting area of research because genome-wide association studies have identified this cytokine as having a key role in viral control, both in the setting of spontaneous resolution of $\mathrm{HCV}$ and also in the context of therapy.,5

The recognition that IFNs play a key role in immunomodulation and antiviral replication was the catalyst for the development and manufacture of exogenous IFNs for use in human disease. ${ }^{6}$ In 1991 the US Food and Drug Administration (FDA) first approved IFNs for the treatment of HCV. In 1998, approval was granted for the use of the guanosine analog, ribavirin, in combination therapy with IFNs. In 2001 further progress was made with the approval of pegylated IFN (PEG-IFN) for use in combination with ribavirin, and this therapy remains to date the gold standard treatment of HCV.

The aim of therapy in the treatment of HCV is long-term viral eradication. Patients who are virus-free six months after the end of treatment are defined as having a sustained viral response to therapy (SVR), and in more than 95\% of cases these patients remain virus-free indefinitely and are effectively cured of their infection. ${ }^{7}$ Treatment with PEG-IFN and ribavirin has an SVR rate of $50 \%-80 \%$, depending on the viral genotype. ${ }^{8}$ However, treatment with IFN therapy is expensive, protracted, and has an extensive side effect profile. Failure to induce an SVR with IFN-based therapies is thought to be due to the ability of HCV to "subvert" the effects of IFN. The extensive side effect profile of IFN, along with frequent treatment failure, has led to the continuing search for novel therapies and vaccines to eradicate and prevent $\mathrm{HCV}$ infection, aiming perhaps ultimately for an IFN-free treatment regime.

This article explores the pharmacodynamics of IFN, how IFN exerts its antiviral effects, and how HCV may subvert these responses. We describe current IFN-based therapies, followed by the host and viral genetic factors that influence the effectiveness and activity of IFN in the HCV-infected host (Table 1). Finally, we describe the new emerging IFNs and how these may impact on disease in the future.

\section{How IFN inhibits viral replication}

Type I IFN is produced in response to viral pathogens that express pathogen-associated molecular patterns (PAMPs) which bind and signal via pathogen-recognition receptors (PRRs). Since HCV is an RNA virus, the PAMP most relevant
Table I Factors determining an increase in activity and effectiveness of interferons

\begin{tabular}{ll}
\hline Host factors & Viral factors \\
\hline Age less than 40 years & Genotypes 2 and 3 \\
Gender; female & Viral load $<2$ million IU \\
Ethnicity; nonblack & Lack of mutations in the ISDR \\
Lack of liver fibrosis & $\begin{array}{l}\text { Decrease in E2 sequence } \\
\text { homology with PKR }\end{array}$ \\
HLA type & $\begin{array}{l}\text { Viral kinetics; rapid decline } \\
\text { with therapy } \\
\text { Increased duration of therapy }\end{array}$ \\
Immune response & \\
IL-28 genetic status &
\end{tabular}

Abbreviations: $H L A$, human leukocyte antigen; ISDR, interferon-sensitive determining region; PKR, protein kinase $\mathrm{R}$.

to HCV infection is double-stranded RNA (dsRNA), that binds to the membrane-bound ligand, toll-like receptor-3 (TLR3). ${ }^{9}$ More recently, it has been shown that dsRNA may also activate interferon regulatory factor 3 (IRF3) in the cell cytosol via retinoic acid-inducible gene 1 (RIG1) and melanoma differentiation-associated gene 5 (MDA5). ${ }^{10}$ Downstream, dsRNA ligation activates IRF3 and NF- $\kappa-\beta$ transcription factors that play a critical role in the induction of IFN.

Type I IFNs are produced not only by virally infected cells, but also by stimulated NK cells, T lymphocytes, and plasmacytoid dendritic cells, the latter being a particularly potent source of IFN- $\alpha$. Proof of principle that HCV does indeed trigger these pathways has been shown by infecting chimpanzees (the only animal model available) with HCV, and demonstrating that the expression of Type I IFNs and IFN-induced genes are induced within the liver early in infection. ${ }^{11}$

Type I IFNs mount an immediate antiviral response through the inhibition of viral replication directly and also indirectly through the modulation of immune cells involved in innate and adaptive antiviral immunity. The direct inhibition of antiviral replication by IFNs occurs via at least three pathways, ie, protein kinase R (PKR), the 2'-5' oligoadenylate synthetase (2'-5'OAS)/ RNAse system, and Mx proteins. When Type I IFNs are generated, they bind to specific IFN-AR receptors, activating the JAK/ STAT signaling pathway. STAT is phosphorylated by JAK1 and Tyk2, and recruits IRF9 to form the ISGF3 complex that binds to the internal ribosomal entry site (IRES) in the promoter region of interferon-stimulated genes (ISG) leading to the expression of PKR, 2'-5'OAS, ISG-p56, 1RF-7, and other ISG. ${ }^{12}$ PKR is activated by dimerization and binding to dsRNA.

Activated PKR induces the phosphorylation and activation of eukaryotic initiation factor (eIF)-2 $\alpha$, which inhibits protein translation and therefore inhibits virion production 
in infected cells. ${ }^{13}$ The $2^{\prime}-5$ ' OAS pathway is an RNA decay pathway activating RNAses and thus degrades virus. ${ }^{14}$ Mx proteins are IFN-induced guanosine triphosphatases that interfere with the replication of negative-strand RNA viruses. ${ }^{15}$ Chimpanzee studies have shown that in acute HCV infection, Type I IFN-induced PKR, 2' $-5^{\prime}$ OAS, and Mx genes are all upregulated, which collectively serve to inhibit replication of viruses and induce apoptosis in infected hepatocytes. ${ }^{16}$

IFNs exert antiviral effects not only through the mechanism outlined above, but also through diverse effects on immune cells. These include the upregulation of human leukocyte antigen (HLA) Class I expression, enhancing the terminal differentiation of dendritic cells, ${ }^{17} \mathrm{~T}$ cell antiproliferative effects, stimulation of IFN- $\gamma$ by CD4 T cells, ${ }^{18}$ and the upregulation of the expression of HCV antigens on the surface of infected hepatocytes via the modulation of immunoproteosomes that are required for the presentation of antigens to the immune system. ${ }^{19}$

\section{HCV subversion of interferon signaling}

Phylogenetic analysis suggests that $\mathrm{HCV}$ has existed in human hosts for more than 1000 years. ${ }^{20}$ During this time HCV has evolved multiple mechanisms to subvert the antiviral effects of IFN (Figures 1 and 2). The HCV virus is approximately 3000 amino acids in length. It is a single-stranded RNA virus with a single open reading frame that is cleaved into its structural (core and envelope proteins) and nonstructural (NS 2, 3, 4, and 5) protein components. Multiple HCV proteins have been shown to inhibit either the production or the effects of IFN, as summarized in Table 2. HCV core protein inhibits the activation and translocation of STAT1 (a key protein in the IFN signaling pathway, see Figure 1), ${ }^{21,22}$ inhibits the function of interferon-stimulated gene factor 3 (ISGF3) via the generation of the suppressor of cytokine signaling 3 (SOCS3), ${ }^{23}$ and blocks DNA binding by ISGF3. ${ }^{24}$

HCV NS3/4A serine protease has been shown to inhibit IFN induction by preventing the phosphorylation of IRF3 $3^{25}$ and also by cleavage of the "Toll-IL-1 receptor domaincontaining adaptor inducing IFN- $\beta$ " (TRIF) protein that links TLR3 to kinases responsible for the activation of IRF3. ${ }^{26}$ $\mathrm{NS} 3 / 4 \mathrm{~A}$ also interferes with IFN induction by disruption of RIG1 signaling. ${ }^{27}$ An in vivo study has shown that IRF3 activation in the livers of patients infected with $\mathrm{HCV}$ is limited. ${ }^{28}$

The HCV NS5A is a protein, the function of which is unknown. It has been reported to induce the cytokine IL-8

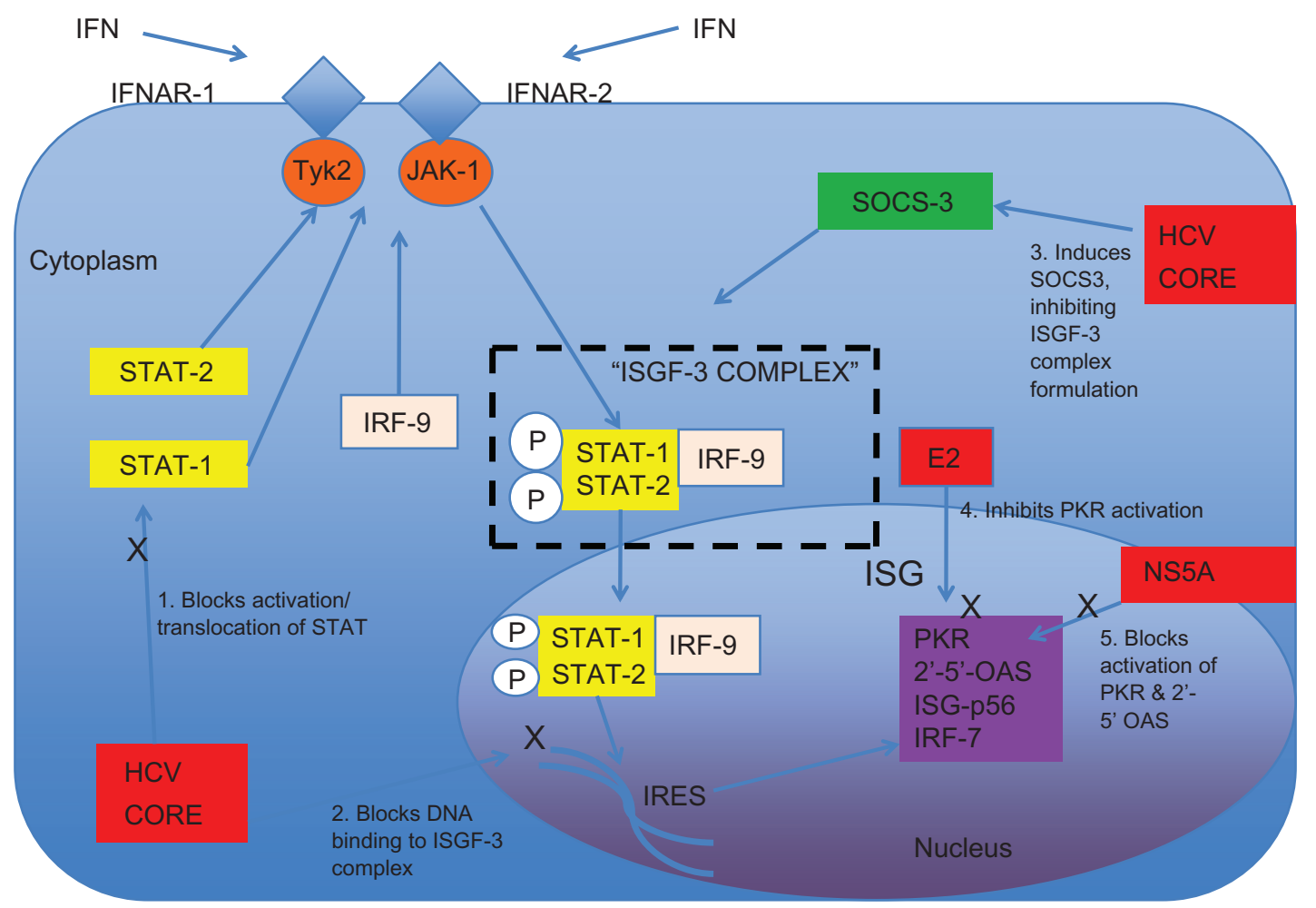

Figure I IFN binds to receptors activating the stimulation of ISG via the JAK/STAT pathway. HCV core (I) inhibits the activation or translocation of STAT, (2) blocks DNA binding to ISGF-3 complex (3) and inhibits the formulation of ISGF-3 by enhancing production of the inhibitory SOCS-3. E2 (4) inhibits the activation of PKR and (5) NS5A inhibits the activation of ''-5'OAS and of PKR. 


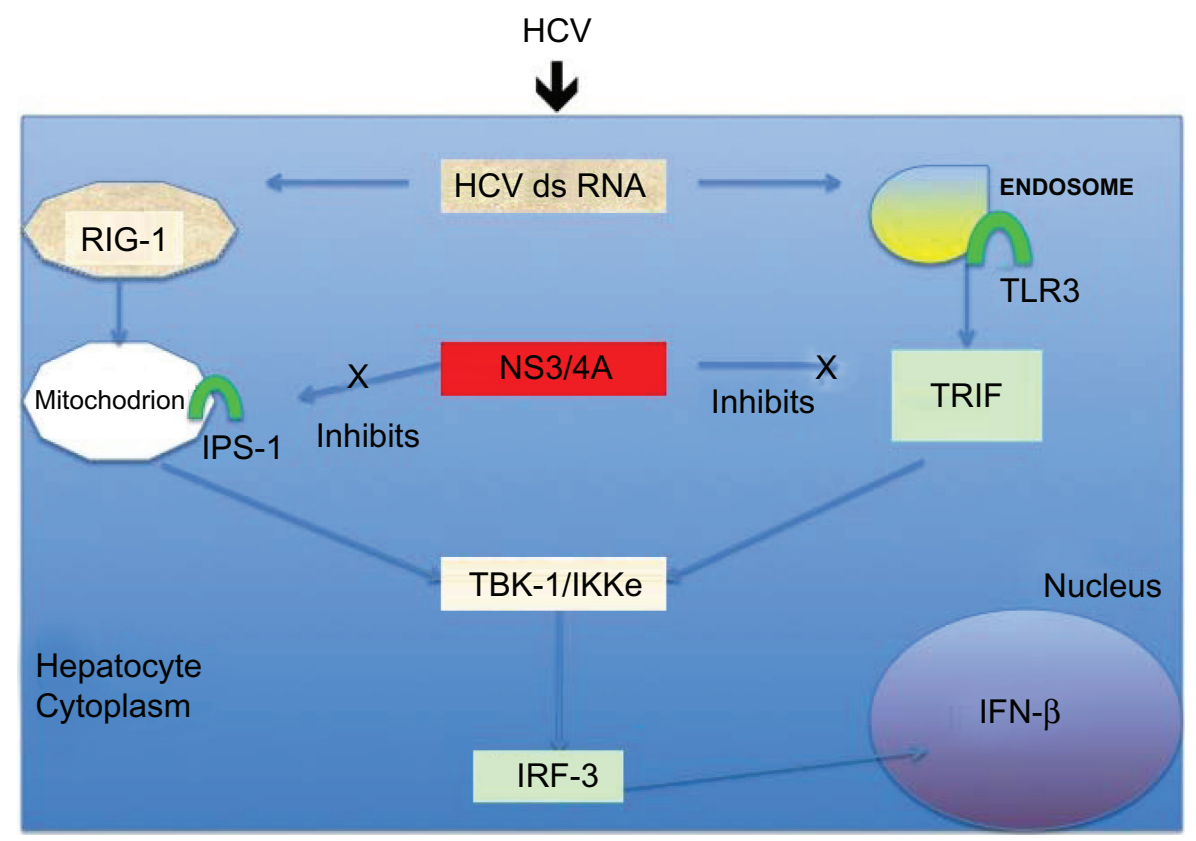

Figure 2 HCV RNA activates IRF3 via the RIGI and TLR3 pathways to induce IFN production. HCV NS3/4 protease inhibits these two pathways by the cleavage of TRIF and IPS-I.

Abbreviations: HCV, hepatitis C virus; IFN, interferon; IRF, interferon regulatory factor; TRIF, "Toll-IL-I receptor domain-containing adaptor inducing IFN- $\beta$ ” protein.

leading to partial inhibition of the IFN antiviral response. ${ }^{29,30}$ NS5A also contains the interferon sensitivity-determining region (ISDR) that may bind and inhibit PKR, ${ }^{31}$ whilst E2 inhibits PKR through sequence homology. ${ }^{32}$ The inhibition of PKR by NS5A and E2 is discussed in detail below.

\section{Current interferon-based therapies IFN and ribavirin for chronic HCV infection}

Following the discovery of the HCV virus in 1989, IFN (nonpegylated) was administered as monotherapy by subcutaneous injection three times a week. This led to SVR rates of only $8 \%$ when given for six months, increasing to $27 \%$ when patients were treated for $1-2$ years. ${ }^{33}$ Following the introduction of ribavirin for administration in combination with IFN in 1998, SVR rates improved markedly to approximately $40 \%$ for HCV genotype 1 infection. ${ }^{34,35}$ Ribavirin is an antiviral nucleoside analog of guanosine. The mechanism of action of ribavirin is unclear because alone this drug has no effect on $\mathrm{HCV}$ viral load, although interestingly ribavirin monotherapy reduces liver inflammation, as measured by the liver enzyme alanine transaminase ${ }^{36}$ Possible mechanisms of action include effects on T cell-mediated immunity for which there is some evidence, ${ }^{37,38}$ inhibition of host cell inosine monophosphatase dehydrogenase, direct inhibition of HCV RNA-dependent RNA polymerase, and the induction of RNA mutagenesis. ${ }^{39}$
The addition of polyethylene glycol (PEG) to IFN was a major advance in the treatment of patients with HCV. Large, randomized, controlled trials demonstrated a significant improvement in SVR rates to approximately $50 \%$ in genotype 1-infected patients when PEG-IFN was combined with ribavirin. ${ }^{8}$ PEG increases the molecular weight of IFN, so delays absorption and degradation, and prolongs the half-life of IFN to over 10 times that of the conventional IFN. Rather than three times a week, PEG-IFN may be administered weekly. Animal studies have found PEG-IFN to have a 12- to 135-fold increase in effect against viruses and a 18 -fold increase in effect against tumor cells..$^{40}$ Two types of PEG-IFN exist and are licensed, ie, PEG-IFN- $\alpha-2 \mathrm{a}$ (Roche) with a $40 \mathrm{kDa}$ branched PEG chain, and PEG-IFN- $\alpha-2 b$ (Schering-Plough) with a $12 \mathrm{kDa}$ linear PEG chain. PEG-IFN- $\alpha-2 \mathrm{a}$ is administered at a fixed dose of $180 \mu \mathrm{g} / \mathrm{week}$, whereas the dose of PEG-IFN- $\alpha-2 b$ is adjusted according to patient weight. PEGIFN- $\alpha-2 a$ is excreted by both the kidneys and the liver, so dose adjustment of this IFN is not required in patients until glomerular filtration rates fall very low. ${ }^{41}$

\section{Treatment for acute HCV infection}

During the primary phase of infection patients are usually asymptomatic. However, a proportion of patients with acute infection will feel nonspecifically unwell, develop jaundice, or will be diagnosed following surveillance testing after 
Table $2 \mathrm{HCV}$ proteins that subvert the production or effects of interferon

\begin{tabular}{|c|c|c|}
\hline HCV protein & Function & Effect \\
\hline Core & Viral capsid protein & $\begin{array}{l}\text { Inhibits STATI activation } \\
\text { Increases STATI degradation } \\
\text { Induces the expression of } \\
\text { SOCS3 } \\
\text { Blocks DNA binding of ISGF3 } \\
\text { Inhibits SOCSI }\end{array}$ \\
\hline E2 & Envelope protein & Sequence homology with PKR \\
\hline NS3/4A & Protease activity & $\begin{array}{l}\text { Inhibits the function of TLR3 } \\
\text { and blocks RIGI signaling }\end{array}$ \\
\hline NS5A & Unknown & $\begin{array}{l}\text { Induces IL-8 } \\
\text { Blocks IFN production through } \\
\text { inhibition of JAK-STAT } \\
\text { signaling } \\
\text { Contains the ISDR that inhibits } \\
\text { PKR }\end{array}$ \\
\hline
\end{tabular}

Abbreviations: $\mathrm{HCV}$, hepatitis $\mathrm{C}$ virus; IFN, interferon; ISDR, interferon-sensitive determining region; PKR, protein kinase $\mathrm{R}$.

exposure to HCV. If virus is still detectable 3-6 months after primary infection, chronic infection is likely to develop. During the first few months of infection the viral kinetics typically fall into one of the three patterns, ie, levels of viremia may remain constantly high through to chronic infection, steadily decline before becoming undetectable long term (spontaneous resolution), or fluctuate, sometimes dramatically, falling to undetectable levels and then increasing again to high viral loads before either resolving or remaining high. For this reason, treatment is typically deferred until 3-6 months after the diagnosis of primary infection when, if the virus is still detectable, chronicity is likely. Whilst large controlled studies in the treatment of chronic $\mathrm{HCV}$ guide management, studies in acute $\mathrm{HCV}$ are much more heterogeneous in terms of trial design, treatment duration, and the types of IFN used to treat infection. However, there is a general consensus that the treatment of choice for acute infection is PEG-IFN for six months, irrespective of viral genotype, and that there is no evidence currently that the addition of ribavirin confers added benefit. A number of studies have shown that the SVR rate for these patients is considerably higher than that typically observed in the treatment of chronically infected patients, with SVR rates of $71 \%-94 \%{ }^{42-44}$ The reasons for the high SVR rates are not known, but most likely relate to the fact that lower numbers of circulating quasispecies are circulating in early infection ${ }^{45}$ or to the fact that the virus has not persisted in the host for long enough to evolve strategies to evade the antiviral effects of IFN.

\section{Viral genetic factors determining effectiveness of IFN $\mathrm{HCV}$ viral genotype}

$\mathrm{HCV}$ viral genotype is the most important factor in predicting the response to IFN-based therapies. HCV can be classified into six genotypes (1-6) based on sequence homology. ${ }^{46}$ The SVR rates using PEG-IFN and ribavirin therapy for genotypes 1 or 4,3 , and 2 are approximately $50 \%, 70 \%$, and $80 \%$, respectively. Sequence homology between different genotypes is approximately $80 \%$ at the amino acid level. HCV genotypes can be further divided into subtypes or variants denoted by lower case letters (1a, 1b, 1c, etc), with more than $50 \mathrm{HCV}$ subtypes reported to date. Usually an individual is infected with a single subtype, although infection with multiple genotypes and subtypes is well recognized. Within each host, $\mathrm{HCV}$ circulates as a number of closely related but distinct viral strains called quasispecies. In fact, $\mathrm{HCV}$ diversity is 10 times greater than that of human immunodeficiency virus (HIV) infection due to the lack of proof reading capacity of the RNA-dependent RNA polymerase. An increase in the number of quasispecies detectable before therapy has been associated with a poorer response to IFN therapy. ${ }^{45}$

Different genotypes prevail in distinct geographic locations; genotype 1 is common in the US and Western Europe, accounting for $60 \%-65 \%$ of infected HCV individuals, genotype 3 is endemic in Pakistan, genotype 4 is largely confined to the Middle East, Egypt, and Central Africa, whilst genotypes 5 and 6 are predominantly found in South America and South East Asia, respectively. Over the last century, intravenous drug use and medical practices have led to an epidemic of a small number of subtypes in the US and Western Europe, including subtypes 1a, 1b, and 3a. The reason why some genotypes are more responsive to therapy than others is currently unknown. It has been suggested that the envelope proteins of genotypes 2 and 3 have less sequence homology with PKR than that of genotype 1, and so are less able to subvert the antiviral effects of IFN. ${ }^{32}$

\section{Interferon sensitivity-determining region}

The ISDR is a small region of the viral genome (amino acids 2209-2248) located within the NS5A region of the HCV $1 b$ subtype that has been reported to determine the effects of exogenous IFN therapy on viral replication via the inhibition of PKR. ${ }^{47,48}$ Studies in Japanese cohorts suggested that patients infected with a wild-type ISDR strain had a poor response to IFN, whereas patients with more than one amino acid mutation within the ISDR had an increased rate of SVR. 
Whilst repeatedly shown to hold true for Asian populations, this correlation was not clearly observed in Caucasian populations, and the observation has remained controversial. ${ }^{49}$ Heterogeneous study designs and IFN treatment protocols, along with a lower prevalence of the mutant ISDR type ( $0 \%-17 \%$ in Western countries compared with $16 \%-42 \%$ in Japanese populations) may at least partially explain this discrepancy. A meta-analysis of viral sequences assessing 675 individual ISDRs with regard to IFN response showed a strong correlation between IFN response and substitutions in the ISDR, giving further credence to the ISDR hypothesis. ${ }^{50}$

\section{Mutations within HCV core protein}

Amino acid substitutions within the $\mathrm{HCV}$ core protein at positions 70 and 91 have been associated with a nonresponse to treatment in Japanese populations infected with the HCV genotype $1 \mathrm{~b}$. The reasons for this are not known but may relate to the ability of this protein to affect IFN signaling through the JAK/STAT pathway. ${ }^{51,52}$ This observation has not been shown in non-Japanese patient groups.

\section{PKR homology domain}

Another way in which HCV reportedly subverts the effectiveness of IFN is through sequence homology between a small region of $\mathrm{E} 2$ and the phosphorylation sites of PKR and eIF2 $\alpha .{ }^{32}$ In this way HCV may act as a "decoy" for key molecules involved in IFN signaling. Sequence homology is greater for genotype 1 than genotypes 2 and 3 , potentially explaining why genotype 1 is more resistant to IFN therapy.

\section{Viral load}

HCV viral load is the number of detectable viral particles in blood. This, in addition to viral genotype, is key in predicting IFN responsiveness. Many studies have shown that the lower the viral load, the more likely a patient is to eradicate virus with IFN-based therapies. A viral load less than $800,000-2,000,000$ copies/mL is associated with a significantly higher probability of achieving SVR following IFN-based therapies. ${ }^{34,53,54}$ In general, lower viral loads are associated with less circulating viral quasispecies and also with a faster time to HCV RNA negativity during treatment, and it may be these factors that are more important in predicting responsiveness to IFN, rather than the viral load per se.

\section{Viral kinetics and duration of therapy}

Following treatment with IFN there is biphasic decline in viral load. Over the first 24 hours, there is a very rapid decline of
0.5-2.5 logs, ie, the first phase, followed by a slower rate of viral decline over subsequent weeks, ie, the second phase. Mathematical modeling has suggested that the first phase of viral decline is due to the direct antiviral effects of IFN and the second phase to the clearance of infected hepatocytes. ${ }^{55}$ There is currently limited experimental data to support this model, and it is also theoretically possible that the first phase of decline is due to inhibition of IFN-sensitive strains, whilst the second phase is due to the slower clearance of relatively IFN-resistant strains.

Assessment of changes in viral load over time in the early weeks of treatment is now used clinically to predict the likelihood of a subsequent SVR. As a general principle, the more quickly a patient becomes HCV RNA-negative after starting treatment, the more likely that the patient is to have an SVR, and an increase in viral decline can be seen as quickly as 24-48 hours after the start of therapy in those who have a subsequent SVR compared with those who do not. ${ }^{56}$ Patients with genotype 2 and 3 infection are likely to have a significantly greater decline in viral load early after starting IFN compared with patients with genotype 1 infection. ${ }^{57}$

The assessment of viral kinetics has led to the definitions of rapid viral response (RVR) and early viral response (EVR), where HCV RNA is undetectable by polymerase chain reaction at four weeks and 12 weeks of therapy, respectively. Patients with an RVR are particularly likely to achieve an SVR, and this has led to a number of clinical studies addressing the concept of tailored treatment, whereby these patients are offered a shorter or longer course of therapy depending on assessment of early viral kinetics.

Assessment of viral load at 12 weeks compared with baseline is also a key parameter in determining therapy duration, and most clinicians would stop therapy at week 12 in patients who do not achieve a 2 log decline in viral load from baseline, because the chances of these patients achieving an SVR with 48 weeks of treatment is as low as 3\%. Current international consensus guidelines state that patients with genotype 1 infection should be treated for 48 weeks with combination therapy and patients with genotypes 2 and 3 for 24 weeks. ${ }^{58}$ Despite the more protracted course of treatment, patients with genotype 1 are less likely (41\%-56\% depending on baseline viral load) to achieve an SVR compared with patients with genotypes 2 and $3(74 \%-81 \%$ depending on baseline viral load). ${ }^{8}$

As baseline viral load, genotype, and rate of viral decline are all known to be independent factors that determine SVR, a number of studies have stratified these factors in both study design and analysis. For example, it has been shown that 
patients who have an RVR may be treated for 24 weeks rather than 48 weeks with comparable rates of SVR, but only if the baseline viral load is low $(<400,000 \mathrm{IU} / \mathrm{mL}) .{ }^{59}$ Other studies assessing tailored treatment regimens for genotype 1 patients have shown that patients treated for less than 48 weeks, following assessment of early viral kinetics have a lower SVR. In one such study of tailored treatment, patients were treated with PEG-IFN- $\alpha-2 b(1.5 \mu \mathrm{g} / \mathrm{kg} /$ week $)$ and ribavirin (800-1400 $\mu \mathrm{g} /$ day) for 48 weeks or for a duration that was determined by time to HCV RNA <615 IU/mL. Viral load was assessed at weeks $3,4,5,6,7$, and 8 , and patients with an HCV RNA <615 IU/mL were treated for 18, 24, 32, 36, 42 , or 46 weeks, respectively. This individualized treatment regime had a lower SVR (34\% versus 48\%, $P=0.004$ ) compared with standard 48 -week therapy (32\% versus $14 \%) .{ }^{60}$ To date, no recommendations or guidelines exist regarding such an individualized approach to treatment for genotype 1 infection.

Large clinical studies have shown that 24 weeks of combination therapy achieves an SVR that is equivalent to that achieved by longer regimens in patients with genotype 2 and 3 infection. ${ }^{8}$ However, regimens shorter than 24 weeks have also been assessed in three European studies in genotype $2 / 3$ patients with an RVR. One of the first pilot studies suggested that very high SVR rates (90\%) could be achieved with only 14 weeks of therapy in patients with an RVR. ${ }^{61}$ A larger, randomized, controlled study in genotype 2 and 3 patients with an RVR showed that patients treated for 12 weeks had a similar SVR to patients treated for 24 weeks. ${ }^{62}$ However, a large study of more than 1500 patients has shown that both genotype 2 and genotype 3 patients treated for 16 weeks compared with 24 weeks of treatment with PEG-IFN- $\alpha-2 \mathrm{a}(180 \mu \mathrm{g} /$ $\mathrm{kg} /$ week) plus ribavirin have significantly lower SVR rates (65\% versus $76 \%$ for genotype 2 and 3 patients, and $65 \%$ versus $82 \%$ for genotype 2 only patients). In this study, a baseline viral load of $<800,000 \mathrm{IU} / \mathrm{mL}$ was an important determinant of SVR. ${ }^{63}$ Therefore, the current recommendation is 24 weeks' treatment in genotype $2 / 3$ patients whilst further larger trials are awaited to clarify the role of shortening the duration of therapy.

\section{Host genetic factors determining effectiveness of IFN Age, gender, and ethnicity}

Age younger than 40 years and female gender have been consistently associated with a more favorable response to IFN therapy. The reason for this difference is not clear, but may relate directly to the effects of increasing age or sex hormones on immune responses that are influenced by IFN therapy. ${ }^{64}$

Responsiveness to IFN is also known to decrease with increasing liver fibrosis. ${ }^{8}$ Although gender and fibrosis have been found to be independent factors in determining IFN responsiveness, male gender is also associated with an increase in liver fibrosis in a number of liver diseases, including $\mathrm{HCV}, \mathrm{HBV}$, and fatty liver disease. Similarly, younger age may be associated with a shorter duration of infection and less fibrosis.

A number of studies have shown that black African Americans have a poor response to IFN-based therapies. ${ }^{65}$ The reasons for this may include a difference in host immune HLA Class I and I allele expression and difference in HCVspecific immunity between different ethnic groups ${ }^{66}$ or racial differences in the expression of the IL28B risk allele. ${ }^{67}$

\section{Antiviral immunity}

Whilst it is clear that the immune response plays a key role in the spontaneous resolution of $\mathrm{HCV}$, studies that have assessed the role of the immune response in determining the outcome of IFN therapy have shown inconsistent findings. Some have suggested that a pre-existing $\mathrm{CD}^{+}$ $\mathrm{T}$ cell response is associated with viral clearance during therapy, ${ }^{68}$ whilst others have shown that the quality of the $\mathrm{T}$ cell response induced during therapy may also be relevant, with an early study suggesting that the addition of ribavirin to IFN therapy was associated with less IL-10 (a Th1 cytokine involved in anti-inflammatory reactions) production by HCV-specific T cells. ${ }^{37}$ Recent reports have shown that, rather than enhancing anti-HCV-specific $\mathrm{T}$ cell responses, IFN therapy may actually be associated with a decrease in antiviral $\mathrm{T}$ cell immunity, either in response to a declining $\mathrm{HCV}$ viral load or as a consequence of the lymphopenia that is induced by this treatment. ${ }^{69}$ Whilst HLA Class I and II associations with spontaneous viral clearance have been made, signifying the importance of $\mathrm{CD}^{+}$and $\mathrm{CD}^{+} \mathrm{T}$ cells in this setting, ${ }^{70}$ studies assessing these alleles in response to IFN have not shown a consistent effect.

Genome-wide association studies have been used to identify host polymorphisms that may be associated with viral clearance in response to IFN therapy. A recent high profile study identified that an SNP (rs12979860) on chromosome $19 q 13$, three kilobases upstream from the start codon of the IL28B (IFN- $\lambda$ ) gene was associated with a near twofold change in response to treatment in both Caucasian and 
African American patients. ${ }^{5}$ This finding was echoed in a further study of 1008 patients from six independent $\mathrm{HCV}$ cohorts in which it was observed that the same polymorphism was linked to the spontaneous resolution of $\mathrm{HCV}^{4}$ Another genome-wide association study of 1362 patients and controls, some of whom were also coinfected with HIV, showed an association with an SNP (rs8099917) in the IL28B locus that is known to be in linkage disequilibrium with the rs 12979860 SNP (this study was unable to detect the rs12979860 SNP because this was not contained on the platform used for SNP detection) and response to IFN therapy (odds ratio 5.19, 95\% confidence interval 2.9-9.3). ${ }^{71}$ This association was not seen with genotype 2 and 3 infection. The mechanistic role of IL-28 in the clearance of HCV is currently not known.

\section{New interferons}

A number of new IFNs have been or are under development with the aim of increasing SVR rates, or requiring dosing less frequently.

\section{Albinterferon}

Albinterferon is a long-acting IFN- $\alpha$ that is a recombinant polypeptide of combined human albumin genetically fused with IFN- $\alpha$. This drug may be administered every two weeks because the median half-life is 148 hours, whereas the halflife of PEG-IFN is 80 hours. A multicenter study evaluated 458 treatment-naïve patients who were randomized to receive either PEG-IFN- $\alpha-2 \mathrm{a}$, or albinterferon every two weeks at a dose of 900 or $1200 \mu \mathrm{g}$, or albinterferon $1200 \mu \mathrm{g}$ every four weeks, in addition to weight-based ribavirin. The SVR rates of the albinterferon $900 \mu \mathrm{g}, 1200 \mu \mathrm{g}$ two weekly, and $1200 \mu \mathrm{g}$ four weekly regimes were $58.5 \%, 55.5 \%$ and $50.9 \%$, respectively, compared with $57.9 \%$ for PEG-IFN. ${ }^{72}$ Therefore, the efficacy of albinterferon combined with ribavirin treatment appears to be comparable with current gold standard treatment with ribavirin and PEG-IFN, but with the added benefit that less frequent injections are required.

\section{Interferon- $\Omega$}

IFN- $\Omega$ is derived from Chinese hamster ovary cells and shares $62 \%$ homology with the amino acid sequence for IFN- $\alpha$ and $33 \%$ with that of IFN- $\beta$. A Phase II study of 102 treatmentnaïve genotype 1 patients, published in abstract form in 2007 , compared IFN- $\Omega$ administered by daily injection $(25 \mu \mathrm{g} /$ day $)$ with combination IFN- $\Omega$ and ribavirin (1000-1200 $\mu \mathrm{g} /$ day). Twelve weeks after completing 48 weeks of therapy, $36 \%$ of patients receiving the combination therapy were virus-free. ${ }^{73}$ SVR rates were not given, but these data do suggest that
IFN- $\Omega$ is less effective than PEG-IFN- $\alpha$ in the treatment of $\mathrm{HCV}$.

\section{Locteron}

Locteron (BLX-883) is a recombinant IFN- $\alpha-2 b$ released via a biodegradable polymeric delivery system. The delivery system consists of polyester or polyether microspheres that are degraded by hydrolysis and oxidation to enable a linear release of compounds. Published Phase I data shows a good safety profile for the compound, with a half-life that is twice as long as that for conventional PEG-IFN. ${ }^{74}$ The stated aim of developing this drug is administration every two weeks. Locteron data was presented in abstract form at the 58th American Association for the Study of Liver disease meeting in 2007. Thirty-two patients were randomized to receive differing doses of subcutaneous Locteron fortnightly with ribavirin. Results showed a -1 to $-5 \log _{10}$ reduction in $\mathrm{HCV}$ viral titers dependent on dose (http://www.octoplus.nl/ index.cfm/octoplus/products/locteron/index.cfm). Further published studies on this compound are awaited.

\section{$M A X Y-\alpha$}

MAXY- $\alpha$ (R7025/ RO5014583) is an IFN- $\alpha$ variant that has been created using "complex molecular technologies" by Maxygen. Preclinical data comparing MAXY- $\alpha$ with PEG-IFN is reported to show that MAXY- $\alpha$ has increased antiviral and immune stimulatory activity (http://www. medicalnewstoday.com/articles/56124.php). However, a double-blind, dose-escalation, controlled Phase I study showed unexpected reductions in pharmacokinetic and pharmacodynamic effects in the majority of patients receiving two doses of MAXY- $\alpha$ and the development of anti-IFN antibodies, leading the manufacturer to place a hold on further development of this compound (http://www.maxygen. com/newsview.php?listid $=282$ ).

\section{Oral interferon}

Belerofon ${ }^{\circledR}$ is a variant of human IFN- $\alpha$ with a single amino acid mutation designed to lower the susceptibility of IFN- $\alpha$ to proteolytic degradation. In animal studies, subcutaneous injections showed a prolonged half-life when compared with native IFN- $\alpha$ and its pegylated forms (http://www.natap.org/2007/ HCV/040907_03.htm). An oral preparation of the compound has been developed, and the manufacturer claims that serum concentrations equivalent to subcutaneous injections of IFN may be obtained after oral ingestion. Published studies in humans are awaited, and a Phase 1 clinical trial is planned (http://www. prnewswire.co.uk/cgi/news/release?id=135767). 


\section{Other noninterferon therapies}

Many small molecules, collectively known as specifically targeted antiviral therapy for HCV (STAT-C) that target the protease and polymerase of $\mathrm{HCV}$ genotype 1 infection are currently in development. Two of these, bocepravir and telapravir, have been assessed in Phase III clinical trials. These drugs given in combination with PEG-IFN and ribavirin increase the SVR rates for treatment-naïve, genotype 1-infected patients to approximately $70 \% .^{75}$ As some patient groups are particularly intolerant of IFN (eg, decompensated cirrhotic patients, renal failure patients, and post-transplantation patients) the need for IFN-free treatment regimes remains. An obvious approach then is to follow the approach already successfully used for the treatment of HIV, ie, combining STAT-C drugs. However, the FDA recently recommended that the combination of two STAT-C drugs should not occur until after completion of Phase IIB trials of the single agent. ${ }^{76}$ It is no coincidence then that the first study of combining two STAT-C agents is being conducted in Australia and New Zealand outside the jurisdiction of the FDA. The INFORM-1 (Interferon-FreeRegiment for Management of HCV Infection) trial explores combination therapy of ITMN-191 (a protease inhibitor) with R7128 (a polymerase inhibitor) for 14 days in treatmentnaïve patients. Preliminary results showed a mean reduction in viral levels of 4.8-5.2 log IU, with no significant adverse events reported (presented at EASL 2009). Other therapies in development include polymerase inhibitors, cyclophilin inhibitors, sorafenib, and therapeutic $\mathrm{T}$ cell vaccines.

\section{Conclusions}

Since the discovery of HCV in 1989, IFN has remained the key therapeutic agent. Major advances over the last two decades have included the addition of ribavirin and the pegylation of IFN. It is likely that by 2012 protease inhibitors specific for genotype $1 \mathrm{HCV}$ will be available to patients. These will be given in combination with PEG-IFN and ribavirin, and will increase SVR rates to approximately $70 \%$. A number of novel IFNs are currently in development that may increase drug effectiveness and compliance. Ultimately, the aim will be for IFN-free treatment regimes using combinations of HCV protease and polymerase inhibitors and, possibly, therapeutic vaccines. The exciting and very recent observation that IFN- $\lambda$ plays a crucial role in the outcome of $\mathrm{HCV}$ infection and IFN therapy will stimulate new avenues of research into $\mathrm{HCV}$ pathogenesis. Meanwhile, ongoing studies into the ways in which HCV subverts the effects of IFN may lead to novel therapeutic avenues.

\section{Acknowledgments}

EB is a clinician-scientist funded by the Medical Research Council, UK, and supported by the Oxford National Institute of Health Research Biomedical Research Council. NR is a Wellcome clinical fellow and specialist registrar in gastroenterology, hepatology, and general medicine on the Oxford rotation.

\section{Disclosure}

The authors report no conflicts of interest in this work.

\section{References}

1. [No authors listed]. Hepatitis C: Global prevalence (update). Wkly Epidemiol Rec. 1999;74:425-427

2. Lauer GM, Walker BD. Hepatitis C virus infection. $N$ Engl J Med. 2001;345:41-52.

3. Isaacs A, Lindenmann J, Valentine RC. Virus interference. II. Some properties of interferon. Proc R Soc Lond B Biol Sci. 1957;147:268-273.

4. Thomas DL, Thio CL, Martin MP, et al. Genetic variation in IL28B and spontaneous clearance of hepatitis C virus. Nature. 2009;461: $798-801$.

5. Ge D, Fellay J, Thompson AJ, et al. Genetic variation in IL28B predicts hepatitis C treatment-induced viral clearance. Nature. 2009;461: 399-401.

6. Rubinstein M, Rubinstein S, Familletti PC, et al. Human leukocyte interferon: Production, purification to homogeneity, and initial characterization. Proc Natl Acad Sci U S A. 1979;76:640-644.

7. Tsuda N, Yuki N, Mochizuki K, et al. Long-term clinical and virological outcomes of chronic hepatitis $\mathrm{C}$ after successful interferon therapy. J Med Virol. 2004;74:406-413.

8. Fried MW, Shiffman ML, Reddy KR, et al. Peginterferon alfa-2a plus ribavirin for chronic hepatitis C virus infection. NEngl J Med. 2002;347: 975-982.

9. Alexopoulou L, Holt AC, Medzhitov R, Flavell RA. Recognition of double-stranded RNA and activation of NF-kappa B by Toll- like receptor 3. Nature. 2001;413:732-738.

10. Kato H, Takeuchi O, Sato S, et al. Differential roles of MDA5 and RIG-1 helicases in the recognition of RNA viruses. Nature. 2006;441: 101-105.

11. Su AI, Pezacki JP, Wodicka L, et al. Genomic analysis of the host response to hepatitis C virus infection. Proc Natl Acad Sci U S A. 2002;99:15669-15674.

12. de Veer MJ, Holko M, Frevel M, et al. Functional classification of interferon-stimulated genes identified using microarrays. J Leukoc Biol. 2001;69:912-920.

13. Roberts WK, Hovanessian A, Brown RE, Clemens MJ, Kerr IM. Interferon-mediated protein kinase and low-molecular-weight inhibitor of protein synthesis. Nature. 1976;264:477-480.

14. Kerr IM, Brown RE. pppA2'p5'A2'p5'A: An inhibitor of protein synthesis synthesized with an enzyme fraction from interferon-treated cells. Proc Natl Acad Sci U S A. 1978;75:256-260.

15. Arnheiter H, Frese M, Kambadur R, Meier E, Haller O. Mx transgenic mice - animal models of health. Curr Top Microbiol Immunol. 1996;206:119-147.

16. Bigger CB, Brasky KM, Lanford RE. DNA microarray analysis of chimpanzee liver during acute resolving hepatitis $\mathrm{C}$ virus infection. J Virol. 2001;75:7059-7066.

17. Luft T, Luetjens P, Hochrein H, et al. IFN-alpha enhances CD40 ligandmediated activation of immature monocyte-derived dendritic cells. Int Immunol. 2002;14:367-380.

18. Brinkmann V, Geiger T, Alkan S, Heusser CH. Interferon alpha increases the frequency of interferon gamma-producing human $\mathrm{CD}^{+} \mathrm{T}$ cells. $J$ Exp Med. 1993;178:1655-1663. 
19. Shin EC, Seifert U, Kato T, et al. Virus-induced type I IFN stimulates generation of immunoproteasomes at the site of infection. J Clin Invest. 2006;116:3006-3014.

20. Pybus OG, Barnes E, Taggart R, et al. Genetic history of hepatitis C virus in East Asia. J Virol. 2009;83:1071-1082.

21. Melen K, Fagerlund R, Nyqvist M, Keskinen P, Julkunen I. Expression of hepatitis $\mathrm{C}$ virus core protein inhibits interferon-induced nuclear import of STATs. J Med Virol. 2004;73:536-547.

22. Lin W, Kim SS, Yeung E, et al. Hepatitis C virus core protein blocks interferon signaling by interaction with the STAT1 SH2 domain. JVirol. 2006;80:9226-9235.

23. Bode JG, Ludwig S, Ehrhardt C, et al. IFN-alpha antagonistic activity of $\mathrm{HCV}$ core protein involves induction of suppressor of cytokine signaling-3. FASEB J. 2003;17:488-490.

24. de Lucas S, Bartolome J, Carreno V. Hepatitis C virus core protein down-regulates transcription of interferon-induced antiviral genes. J Infect Dis. 2005;191:93-99.

25. Foy E, Li K, Wang C, et al. Regulation of interferon regulatory factor-3 by the hepatitis C virus serine protease. Science. 2003;300:1145-1148.

26. Li K, Foy E, Ferreon JC, et al. Immune evasion by hepatitis $\mathrm{C}$ virus NS3/4A protease-mediated cleavage of the Toll-like receptor 3 adaptor protein TRIF. Proc Natl Acad Sci U S A. 2005;102:2992-2997.

27. Meylan E, Curran J, Hofmann K, et al. Cardif is an adaptor protein in the RIG-1 antiviral pathway and is targeted by hepatitis C virus. Nature. 2005;437:1167-1172.

28. Lau DT, Fish PM, Sinha M, et al. Interferon regulatory factor-3 activation, hepatic interferon-stimulated gene expression, and immune cell infiltration in hepatitis C virus patients. Hepatology. 2008;47: 799-809.

29. Polyak SJ, Khabar KS, Paschal DM, et al. Hepatitis C virus nonstructural $5 \mathrm{~A}$ protein induces interleukin-8, leading to partial inhibition of the interferon-induced antiviral response. J Virol. 2001;75:6095-6106.

30. Polyak SJ, Khabar KS, Rezeiq M, Gretch DR. Elevated levels of interleukin- 8 in serum are associated with hepatitis $\mathrm{C}$ virus infection and resistance to interferon therapy. J Virol. 2001;75:6209-6211.

31. Gale MJ Jr, Korth MJ, Katze MG. Repression of the PKR protein kinase by the hepatitis $\mathrm{C}$ virus NS5A protein: A potential mechanism of interferon resistance. Clin Diagn Virol. 1998;10:157-162.

32. Taylor DR, Shi ST, Romano PR, Barber GN, Lai MM. Inhibition of the interferon-inducible protein kinase PKR by HCV E2 protein. Science. 1999;285:107-110.

33. Carithers RL Jr, Emerson SS. Therapy of hepatitis C: Meta-analysis of interferon alfa-2b trials. Hepatology. 1997;26:83S-88S.

34. McHutchison JG, Gordon SC, Schiff ER, et al. Interferon alfa-2b alone or in combination with ribavirin as initial treatment for chronic hepatitis C. Hepatitis Interventional Therapy Group. $N$ Engl J Med. 1998;339:1485-1492.

35. Davis GL, Esteban-Mur R, Rustgi V, et al. Interferon alfa-2b alone or in combination with ribavirin for the treatment of relapse of chronic hepatitis C. International Hepatitis Interventional Therapy Group. N Engl J Med. 1998;339:1493-1499.

36. Dusheiko G, Main J, Thomas H, et al. Ribavirin treatment for patients with chronic hepatitis C: Results of a placebo-controlled study. J Hepatol. 1996;25:591-598.

37. Cramp ME, Rossol S, Chokshi S, et al. Hepatitis C virus-specific T-cell reactivity during interferon and ribavirin treatment in chronic hepatitis C. Gastroenterology. 2000;118:346-355.

38. Barnes E, Salio M, Cerundolo V, et al. Impact of alpha interferon and ribavirin on the function of maturing dendritic cells. Antimicrob Agents Chemother. 2004;48:3382-3389.

39. Lutchman G, Danehower S, Song BC, et al. Mutation rate of the hepatitis C virus NS5B in patients undergoing treatment with ribavirin monotherapy. Gastroenterology. 2007;132:1757-1766.

40. Son MJ, Song HS, Kim MH, et al. Synergistic effect and condition of pegylated interferon alpha with paclitaxel on glioblastoma. Int J Oncol. 2006;28:1385-1392.

41. Foster GR. Review article: Pegylated interferons: chemical and clinical differences. Aliment Pharmacol Ther. 2004;20:825-830.
42. Santantonio T, Medda E, Ferrari C, et al. Risk factors and outcome among a large patient cohort with community-acquired acute hepatitis C in Italy. Clin Infect Dis. 2006;43:1154-1159.

43. Wiegand J, Buggisch P, Boecher W, et al. Early monotherapy with pegylated interferon alpha-2b for acute hepatitis $\mathrm{C}$ infection: The HEP-NET acute-HCV-II study. Hepatology. 2006;43:250-256.

44. Maheshwari A, Ray S, Thuluvath PJ. Acute hepatitis C. Lancet. 2008; 372:321-332.

45. Farci P, Strazzera R, Alter HJ, et al. Early changes in hepatitis C viral quasispecies during interferon therapy predict the therapeutic outcome. Proc Natl Acad Sci U S A. 2002;99:3081-3086.

46. Simmonds P, Alberti A, Alter HJ, et al. A proposed system for the nomenclature of hepatitis C viral genotypes. Hepatology. 1994;19: 1321-1324.

47. Enomoto N, Sakuma I, Asahina Y, et al. Mutations in the nonstructural protein $5 \mathrm{~A}$ gene and response to interferon in patients with chronic hepatitis C virus 1b infection. N Engl J Med. 1996;334:77-81.

48. Gale M Jr, Blakely CM, Kwieciszewski B, et al. Control of PKR protein kinase by hepatitis $\mathrm{C}$ virus nonstructural 5A protein: Molecular mechanisms of kinase regulation. Mol Cell Biol. 1998;18:5208-5218.

49. Zeuzem S, Lee JH, Roth WK. Mutations in the nonstructural 5A gene of European hepatitis $\mathrm{C}$ virus isolates and response to interferon alfa. Hepatology. 1997;25:740-744.

50. Witherell GW, Beineke P. Statistical analysis of combined substitutions in nonstructural $5 \mathrm{~A}$ region of hepatitis $\mathrm{C}$ virus and interferon response. J Med Virol. 2001;63:8-16.

51. Akuta N, Suzuki F, Sezaki H, et al. Predictive factors of virological non-response to interferon-ribavirin combination therapy for patients infected with hepatitis $\mathrm{C}$ virus of genotype $1 \mathrm{~b}$ and high viral load. $J \mathrm{Med}$ Virol. 2006;78:83-90.

52. Akuta N, Suzuki F, Hirakawa M, et al. Amino acid substitutions in the hepatitis $\mathrm{C}$ virus core region of genotype $1 \mathrm{~b}$ affect very early viral dynamics during treatment with telaprevir, peginterferon, and ribavirin. J Med Virol. 2010;82:575-582.

53. Poynard T, Marcellin P, Lee SS, et al. Randomised trial of interferon alpha2b plus ribavirin for 48 weeks or for 24 weeks versus interferon alpha2b plus placebo for 48 weeks for treatment of chronic infection with hepatitis $\mathrm{C}$ virus. International Hepatitis Interventional Therapy Group (IHIT). Lancet. 1998;352:1426-1432.

54. Shiratori Y, Kato N, Yokosuka O, et al. Predictors of the efficacy of interferon therapy in chronic hepatitis $\mathrm{C}$ virus infection. Tokyo-Chiba Hepatitis Research Group. Gastroenterology. 1997;113:558-566.

55. Neumann A, Lam N, Dahari H, et al. HCV Viral dynamics in vivo and the efficacy of Interferon alpha therapy. Science. 1998;282:103-107.

56. Boulestin A, Kamar N, Sandres-Saune K, et al. Twenty-four hour kinetics of hepatitis $\mathrm{C}$ virus and antiviral effect of alpha-interferon. $\mathrm{J} \mathrm{Med}$ Virol. 2006;78:365-371.

57. Neumann AU, Lam NP, Dahari H, et al. Differences in viral dynamics between genotypes 1 and 2 of hepatitis C virus. J Infect Dis. 2000;182: 28-35.

58. Strader DB, Wright T, Thomas DL, Seeff LB. Diagnosis, management, and treatment of hepatitis C. Hepatology. 2004;39:1147-1171.

59. Mangia A, Minerva N, Bacca D, et al. Individualized treatment duration for hepatitis $\mathrm{C}$ genotype 1 patients: A randomized controlled trial. Hepatology. 2008;47:43-50.

60. Berg T, Weich V, Teuber G, et al. Individualized treatment strategy according to early viral kinetics in hepatitis $\mathrm{C}$ virus type 1 -infected patients. Hepatology. 2009;50:369-377.

61. Dalgard O, Bjoro K, Hellum KB, et al. Treatment with pegylated interferon and ribavarin in HCV infection with genotype 2 or 3 for 14 weeks: A pilot study. Hepatology. 2004;40:1260-1265.

62. Mangia A, Santoro R, Minerva N, et al. Peginterferon alfa-2b and ribavirin for 12 vs. 24 weeks in HCV genotype 2 or 3. $N$ Engl J Med. 2005;352:2609-2617.

63. von Wagner M, Huber M, Berg T, et al. Peginterferon-alpha-2a (40KD) and ribavirin for 16 or 24 weeks in patients with genotype 2 or 3 chronic hepatitis C. Gastroenterology. 2005;129:522-527. 
64. Yuan Y, Shimizu I, Shen M, et al. Effects of estradiol and progesterone on the proinflammatory cytokine production by mononuclear cells from patients with chronic hepatitis C. World J Gastroenterol. 2008; 14:2200-2207.

65. McHutchison JG, Poynard T, Pianko S, et al. The impact of interferon plus ribavirin on response to therapy in black patients with chronic hepatitis C. The International Hepatitis Interventional Therapy Group. Gastroenterology. 2000;119:1317-1323.

66. McCarthy JJ, Li JH, Thompson A, et al. Replicated association between an IL28B gene variant and a sustained response to pegylated interferon and ribavirin. Gastroenterology. 2010;138:2307-2314.

67. Rosen HR, Weston SJ, Im K, et al. Selective decrease in hepatitis C virus-specific immunity among African Americans and outcome of antiviral therapy. Hepatology. 2007;46:350-358.

68. Pilli M, Zerbini A, Penna A, et al. HCV-specific T-cell response in relation to viral kinetics and treatment outcome (DITTO-HCV project). Gastroenterology. 2007;133:1132-1143.

69. Barnes E, Gelderblom HC, Humphreys I, et al. Cellular immune responses during high-dose interferon-alpha induction therapy for hepatitis C virus Infection. J Infect Dis. 2009;199:819-828.

70. Neumann-Haefelin C, Timm J, Schmidt J, et al. Protective effect of human leukocyte antigen B27 in hepatitis $\mathrm{C}$ virus infection requires the presence of a genotype-specific immunodominant CD8+ T-cell epitope. Hepatology. 2010;51:54-62.
71. Rauch A, Kutalik Z, Descombes P, et al. Genetic variation in IL28B is associated with chronic hepatitis $\mathrm{C}$ and treatment failure: A genomewide association study. Gastroenterology. 2010;138:1338-1345 e7.

72. Zeuzem S, Yoshida EM, Benhamou Y, et al. Albinterferon alfa- $2 b$ dosed every two or four weeks in interferon-naive patients with genotype 1 chronic hepatitis C. Hepatology. 2008;48:407-417.

73. Novozenov VZ, Vinogradova E, Nikitin I, et al. Phase II study of omega interferon alone or in combination with ribavarin in subjects with chronic hepatitis C genotype 1 infections. J Hepatol. 2007;46:S8.

74. De Leede LG, Humphries JE, Bechet AC, et al. Novel controlled-release Lemna-derived IFN-alpha2b (Locteron): pharmacokinetics, pharmacodynamics, and tolerability in a phase I clinical trial. J Interferon Cytokine Res. 2008;28:113-122.

75. McHutchison JG, Everson GT, Gordon SC, et al. Telaprevir with peginterferon and ribavirin for chronic HCV genotype 1 infection. N Engl J Med. 2009;360:1827-1838.

76. Sherman KE, Fleischer R, Laessig K, et al. Development of novel agents for the treatment of chronic hepatitis $\mathrm{C}$ infection: Summary of the FDA Antiviral Products Advisory Committee recommendations. Hepatology. 2007;46:2014-2020.

\section{Publish your work in this journal}

The International Journal of Interferon, Cytokine and Mediator Research is an international, peer-reviewed, open-access, online journal. The focus of the journal is to publish original research, reports, editorials, reviews and commentaries on all aspects of interferon, cytokine and mediators of inflammation from labora- tory science to therapeutic indications and clinical studies. The manuscript management system is completely online and includes a very quick and fair peer-review system, which is all easy to use. Visit http://www.dovepress.com/testimonials.php to read real quotes from published authors. 